\title{
Teaching at the bedside: a new model
}

\author{
REGINA W. JANICIK ${ }^{1} \&$ KATHLYN E. FLETCHER ${ }^{2}$ \\ ${ }^{1}$ New York University School of Medicine, Division of Primary Care, Department of Medicine, \\ New York, NY, USA; ${ }^{2}$ Robert Wood Johnson Clinical Scholar/Veterans Administration \\ Scholar, University of Michigan, Ann Arbor, MI, USA
}

SUMMARY The patient is at the center of clinical medicine. In order to effectively teach clinical skills a teacher must learn to involve patients in the educational process. It is through this process that learners acquire the skills of observation, communication, examination and professionalism. Despite the importance of teaching with the patient present, many clinical teachers are hesitant to teach at the bedside. This paper describes a workshop on bedside teaching. The authors present barriers and advantages discussed during the workshop as well as a 'Model of Best Bedside Teaching Practices', which emerged after conducting the workshop for over 135 medical educators. The model includes suggested skills for effective bedside teaching that are arranged into three domains: attending to patient comfort, focused teaching and group dynamics.

\section{Introduction}

There should be "no teaching without the patient for a text, and the best teaching is often that taught by the patient himself" (Bliss, 1999). These are the words of one of the best-loved clinician-educators, William Osler, who strongly believed in teaching students at the patient's bedside. In modern times our definition of bedside teaching includes any teaching done in the presence of the patient, regardless of the setting (e.g. ambulatory clinic, inpatient ward or conference room). Studies have shown that house staff value attending physicians who stress aspects of care such as the doctorpatient relationship and the psychosocial aspects of medicine (Wright et al., 1998), which are both best taught at the bedside. Certain situations require bedside teaching such as demonstrating and practicing physical diagnosis, communication and procedural skills. Besides these educational advantages, there is evidence that patients favor bedside teaching and report better understanding of their illness (Lehmann et al., 1997; Linfors \& Neelon, 1980; Nair et al., 1997) after participating in bedside teaching.

Despite the many reasons to go to the bedside, many physicians are not comfortable with bedside teaching and do not go into patients' rooms with the intention to teach (Miller et al., 1992; LaCombe, 1997). This reluctance has created a generation of teachers uncomfortable and unfamiliar with the basic principles of teaching at the bedside. Unfortunately there are no empiric data as to which teaching strategies are most effective at the bedside. This paper reports our experience of conducting a structured experiential workshop on bedside teaching with a variety of medical educators. After conducting the workshop at national and local meetings and with different levels of teachers (residents, junior and senior faculty) several empiric strategies emerged. In this paper we will outline the workshop and discuss our findings.

\begin{abstract}
Methods
The workshop goals were to encourage participants to reflect on the barriers, advantages and strategies of bedside teaching and then to practice these strategies. The program included a brainstorming session to identify advantages and barriers, a videotape review of an actual bedside teaching encounter, and a group discussion of strategies used in the video and from participants' own experiences. The authors initially generated a list of strategies based on a literature review. This list continued to take form as workshop participants reflected on the video and their own experiences. We found many of the participants' comments fit within our prior collection of strategies. After conducting the workshop several times a consistent 'Model of Best Teaching Practices' emerged. Later on, we incorporated a role-play into the workshop in order to give participants a chance to practice specific skills and receive feedback about their use. At the end of the workshop participants were given a card outlining the model.

The workshop lasted 90 minutes and used active, experiential techniques. Participants had an opportunity to discuss attitudes about and skills used in bedside teaching. Most importantly they had a chance to practice and receive feedback. Finally, they completed a questionnaire designed to measure three outcomes of the workshop (using a Likert scale, $1=$ do not agree, $5=$ strongly agree): whether they have an increased appreciation for bedside teaching, will increase the use of bedside teaching, or will change their teaching as a result of this workshop.
\end{abstract}

\section{Results}

The workshop has been done six times, for a total of 135 participants. The settings included the 2000 SGIM National Meeting, University of Chicago Intern to Junior Resident Orientation, NYU Medical Education Colloquia, Evanston Hospital Intern Retreat and University of Chicago Conference 'Teaching Skills for the Medical Educator'. Sixty-seven post workshop evaluations were completed; means (SD) for each of the three respective outcomes were: 4.2 (0.6), 3.9 (0.6) and $4.3(0.7)$, respectively. Additionally all SGIM workshops were evaluated by participants on a five-point scale from poor to outstanding ( $4=$ above average). The overall mean score for our workshop (35 participants, 22 filled-out evaluations) was 4.1 (0.6).

As a result of the brainstorming section, a list of barriers and advantages were collected and the most commonly

Correspondence: Regina Janicik, MD, New York University School of Medicine, Division of Primary Care, 550 1st Avenue, New York, New York 10012, USA Tel: 212-263-2304; fax: 212-263-8234; email: janicr01@ med.nyu.edu 
Table 1. Most commonly mentioned barriers and advantages.

Barriers:
Fear of patient discomfort
Lack of privacy, confidentiality
Patients are often hard to locate (testing, operating room)
Learners do not want to go to bedside
Takes more time
Teachers feel uncomfortable (may lead to discussion of
medicine teacher not familiar with)
Advantages:
Opportunity to:
- gather additional information from the patient
- directly observe students' skills
- role model skills and attitudes
Humanizes care by involving patients
Encourages the use of understandable and
non-judgmental language
Active learning process in which adults learn best
Patients feel activated and part of the learning
Improves patients' understanding of their disease and
the work-up

Table 2. 'Model of Best Bedside Teaching Practices'.

Domain 1. Attend to Patient's Comfort
Skills:
Ask ahead of time
Introduce everyone to the patient
Brief overview from primary person caring for patient
Explanations to patient throughout, avoid technical language
Base teaching on data about that patient
Genuine, encouraging closure
Return visit by a team member to clarify misunderstandings
Domain II. Focused Teaching
Skills: Microskills of teaching-modified for the bedside
- Diagnose the patient
- Diagnose the learner
Observe
Question
Targeted teaching
Role model
Practice
Teach general concepts
Give feedback
Domain III. Group Dynamics
Skills:
Limit time and goals for the session
Include everyone in teaching and feedback

mentioned are listed in Table 1. The Model of Best Bedside Teaching Practices, which was based on our literature review (particularly Schwenk \& Whitman, 1993) and participant comments, is given in Table 2 . The specific skills used are arranged temporally in a Model Bedside Teaching Session shown in Figure 1.

\section{Discussion}

Despite many reasons to go to the bedside, there was resistance by both teachers and learners. One common misconception was that bedside rounds might upset patients. These concerns have been refuted by several studies, which have found that patients enjoyed bedside rounds and few were upset. Lehmann et al. (1997) found that bedside rounds were not upsetting in $87 \%$ of patients and $82 \%$ felt they should continue. Linfors \& Neelon (1980) found that $94 \%$ of patients surveyed were pleased with bedside rounds and that no patient found them inappropriate. Nair et al. (1997) reported that $77 \%$ enjoyed bedside teaching and $93 \%$ felt it was appropriate. In addition, bedside teaching improved outcomes with 50-68\% (Linfors \& Neelon, 1980; Lehmann et al., 1997; Nair et al., 1997) of patients reporting that they understood their illness better after bedside rounds.

Another barrier was tired, unmotivated house staff. Effective bedside rounds must take into consideration the attention of the team and the team goals. By actively involving the team, bedside rounds are potentially more invigorating and interesting than conference room rounds. Learners also felt that bedside rounds often required more time and repeated parts of the history and physical exam that had already been discussed. Therefore, the teacher must set specific goals and time limits for bedside teaching. Topics that are best taught at the bedside should be reserved for this time.

Teachers also cited lack of confidence in their own ability to teach at the bedside as a barrier, specifically with regard to facing the unknown in front of a patient. Teachers can become more comfortable by realizing that bedside rounds can be focused, particularly on aspects of the case with which the teacher is familiar.

Participants voiced many advantages including improved patient outcomes and opportunities to teach learners how to interact with patients. The main concern was: how can teachers overcome the barriers in order to benefit from all the advantages?

\section{A 'Model of Best Bedside Teaching Practices'}

As a result of a careful review of relevant literature (Cox, 1993; Schwenk \& Whitman, 1993; Kroenke et al., 1997) and input from workshop participants, we developed the following Model of Best Bedside Teaching Practices. The Model includes three domains: Attending to patient comfort, Focused teaching, and Group dynamics, each of which has specific goals and skills. After each iteration of our workshop the model was updated and refined; the latest version is shown in Table 2 . The rationale behind each domain and the skills included are discussed below.

The goal of domain 1 is to remain patient centered and respectful, which will maximize positive outcomes for both the learner and patient. The specific skills outlined have been previously stated by patients (Lehmann et al., 1997; Linfors \& Neelon, 1980) and educators (Schwenk \& Whitman, 1993). The skills may seem self-explanatory but it is worthwhile to clarify their implications. Also, as bedside teaching may occur in different contexts, some skills may be more applicable than others. For example, on attending rounds the patient and team will often already know each other and have an ongoing relationship, versus a physical diagnosis session where the patient may be meeting the learners for the first and only time. 


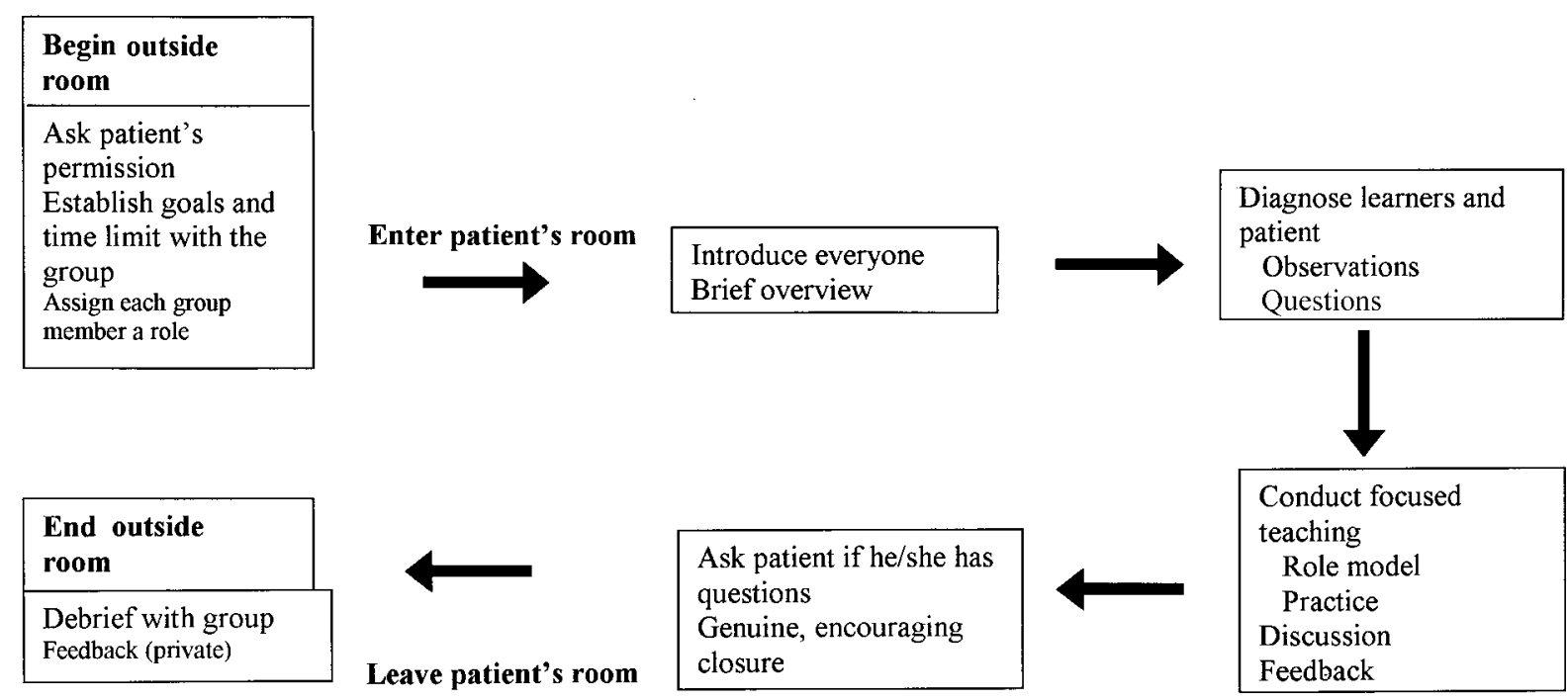

Maintain throughout

Patient Centered (avoid

technical language, base

teaching on that individual)

Include everyone!

Follow-up with

patient

Figure 1. Model beside teaching session.

Domain 1 begins with a suggestion to ask the patient ahead of time. This serves three purposes: it is ethical (patients must have a real opportunity to refuse), it allows the patient to have more control over his/her hospital course, and the patient can be told what to expect (duration, participants and purpose). Second, an introduction of all the visitors serves two purposes: some patients prefer it (Lehmann et al., 1997) and learners may be more invested in the process if they are identified by name rather than as 'the student or resident'. Third, hearing a brief overview of the patient's history can be accomplished by either the person primarily responsible for her/him or by the patient herself/himself. Fourth, avoiding technical language while at the bedside is a request of patients (Nair et al., 1997), and explaining findings directly to the patient was also embraced by Osler (Miller et al., 1992). To this end, assigning a team member the task of noticing the language used during the interaction could bring this aspect of maintaining patients' comfort to the conscious level. It may also enhance the attention of that learner during the session. Fifth, in order to minimize the risk of confusing the patient with an unlikely differential diagnosis, teaching should be based on data about the patient. This means that 'what if' conversations (e.g. 'What if Mrs Smith had a rash along with her enlarged liver?') are best left to the conference room before or after the patient is seen by the group.

Finally, as the session closes the use of a genuine, encouraging closure can help with the potentially awkward endings of bedside teaching interactions. It seems natural to want to reassure the patient as we leave the room that he/she is improving or doing well but sometimes that is not the case.
In those instances a sincere 'thank you for helping to teach future physicians' is often enough to make the patients realize that they have contributed importantly to the learners' training. Afterwards, it is also wise to assign a team member to check whether the patient has further questions about what occurred during the teaching session.

The goals of domain 2 are to conduct an effective teaching session in a focused manner that is relevant to an individual patient's and learner's needs. The specific skills are based on a previously described model, 'The Microskills of Teaching' (Neher et al., 1992) but adapted for teaching at the bedside. The Microskills are used to effectively and efficiently assess, instruct and give feedback and involve three steps: diagnosing the patient, diagnosing the learner and targeted teaching. Diagnosing the patient can be done by having the student present the patient's history and physical examination at the bedside or at another location, or by personally obtaining this information from the patient. Studies show that patients like bedside presentations by learners but learners may not (Simons et al., 1989; Wang-Cheng et al., 1989). One can diagnose the learner by directly observing a student's communication and physical exam skills or by asking effective questions. This information gathered about the learners is then used to target the teaching to their specific needs. Several methods can be used. These include role modeling, assisting the student with a procedure or physical exam skill, teaching general concepts (remember to include the patient) or actively involving the patient as a teacher. Specifically, patients can provide helpful feedback on communication and other skills and insight into their own experiences. 
It is also important to give the learner both positive and corrective feedback as this is an essential component of effective learning. General principles for giving feedback are described elsewhere (Ende, 1983). The feedback should be given as soon as possible after the observation to take advantage of immediacy. If the feedback is negative one must decide if it should be given privately but most times feedback should become part of the group experience.

The goal of domain 3 is to keep the entire group active during the session. This is crucial to the success of a bedside teaching encounter. Skills used include setting goals (both as a group and individually) before entering the room and setting a time limit. All participants should have some role in the encounter. Once in the room the teacher needs to pay attention to the entire group (learners, patients, others in the room). It is important to actively involve quieter members and control dominant members. Patients are also active participants in the group and should be encouraged to teach and ask questions. The final step is to review the session with the group and to answer any questions.

\section{Conclusion}

From these workshops it is clear that there is both enthusiasm and reluctance to teach at the bedside. The 'Model of Best Bedside Teaching Practices' may help enthusiastic teachers overcome reluctance and move more teaching to the bedside.

The next step is to see if these practices lead to important changes in learner or patient outcomes. These include improved knowledge, skills or attitudes of learners (communication, physical exam, psychosocial) and improved satisfaction or education of patients. These are complicated endpoints to consider, especially when we must define what constitutes bedside teaching. A broad definition includes any teaching that is done in the presence of the patient. These versatile, teachable moments can range in focus from interviewing, obtaining consent and delivering bad news to the more conventional components such as learning the physical exam and performing procedures. Teaching with the participation of patients can be rewarding and beneficial to all parties involved but further research into measurable outcomes is certainly needed to determine exactly what those benefits are and how best to accomplish them.

\section{Practice points}

- Potential barriers to teaching at the bedside include those relating to physician teachers, patients and students.

- Advantages include the ability to directly observe clinical skills, improve patient care and enhance learning.

- Specific bedside teaching strategies can alleviate many of the barriers and include: attending to the patient's comfort, using focused teaching methods and managing group dynamics.

\section{Acknowledgements}

The authors would like to thank Drs Jeffrey Teuteberg and Shannon Carson for their help with the creation of the workshop and Drs Adina Kalet, Diane Altkorn and Mark Schwartz for their editing help and advice.

Work was completed while Dr Janicik was receiving funding from the Josiah Macy $\mathrm{Jr}$ Foundation as Project Administrator for the Macy Initiative in Health Communication.

\section{Notes on contributors}

KATHLYN E. FletcheR, MD, is a general internist with an interest in medical education. At the time this workshop was designed she was a resident in internal medicine at the University of Chicago. Currently, she is participating in the Robert Wood Johnson Clinical Scholars Program and Veterans Administration Fellow at the University of Michigan.

REgINA W. JANICIK, MD, is a general internist at New York University. She completed a residency in internal medicine at the University of Chicago and a fellowship at NYU in medical education. During her fellowship she worked on the Macy Initiative in Health Communication as co-leader of curriculum and faculty development efforts.

\section{References}

Burss, M. (1999) William Osler: A Life in Medicine (New York, Oxford University Press), p. 239.

Cox, K. (1993) Planning bedside teaching, Medical fournal of Australia, 158, pp. 280-282, 355-357, 417-418, 493-495, 571-572, 607-608, 789-790.

ENDE, J. (1983) Feedback in clinical medical education, fournal of the American Medical Association, 250, pp. 777-781.

Kroenke, K., Omori, D.M., Landry, F.J. \& Lucey, C.R. (1997) Bedside teaching, Southern Medical fournal, 90, pp. 1069-1074.

Lacombe, M. (1997) On bedside teaching, Annals of Internal Medicine, 126, pp. 217-220.

Lehmann, L.S., Brancati, F.L., Chen, M., Roter, D., Dobs, A.S. (1997) The effect of bedside case presentations on patients' perceptions of their medical care, New England fournal of Medicine, 336, pp. $1150-1155$.

Linfors, E.W. \& NeELon, F.A. (1980) The case for bedside rounds, New England fournal of Medicine, 303, pp. 1230-1233.

Miller, M., Johnson, B., Greene, H.L., Baier, M. \& Nowlin, S. (1992) An observational study of attending rounds, fournal of General Internal Medicine, 7, pp. 646-648.

Nair, B.R., Coughlan, F.L. \& Hensley, M.F. (1997) Student and patient perspectives on bedside teaching, Medical Education, 31, pp. 341-346.

Neher, J.O., Gordon, K.C., Meyer, B. \& Stevens, N. (1992) A fivestep microskills model of clinical teaching, fournal of the American Board of Family Practice, 5, pp. 419-424.

SCHWENK, T.L. \& WhitMAN, N. (1993) Residents as teachers: a guide to educational practice, Salt Lake City, University of Utah School of Medicine, Department of Family and Preventive Medicine, pp. 51-62.

Simons, R.J., Baily R.G., Zelis, R. \& Zwillich C.W. (1989) The physiological and psychological effects of the bedside presentation, New England fournal of Medicine, 321, pp. 1273-1275.

Wang-Cheng, R.M., Banas, G.P., Sigmann, P., Riendl, P.A. \& YounG, M.J. (1989) Bedside case presentations: why patients like them but learners don't, fournal of General Internal Medicine, 4, pp. 284-287.

Wright, S.M., Kern, D.E., Kolodner, K., Howard, D.M. \& BRANCATI, F.L. (1998) Attributes of excellent attending-physician role models, New England fournal of Medicine, 339, pp. 1986-1993. 